Decoding emotion in drug-abusers

\title{
Decoding emotion in drug abusers: evidence for face and body emotion recognition and for disgust emotion
}

\author{
Natale Salvatore Bonfiglio ${ }^{1,2}$; Roberta Renati ${ }^{2,3}$; Gabriella Bottini ${ }^{3,4,5}$ \\ ${ }^{1}$ Department of Psychology "Renzo Canestrari”. University of Bologna \\ ${ }^{2}$ Noah srl, Pavia. \\ ${ }^{3}$ Department of Brain and Behavioral Science, University of Pavia, Pavia, Italy. \\ ${ }^{4}$ Cognitive Neuropsychology Center, ASST Grande Ospedale Metropolitano Niguarda of \\ Milan, Italy \\ ${ }^{5}$ NeuroMi, Milan Center for Neuroscience, Milano, Italy
}

Corresponding author:

Natale Salvatore Bonfiglio; e-mail: s.bonfiglio@unibo.it

Viale Carlo Berti Pichat, 5, 40127 Bologna BO

\begin{abstract}
Background: Different drugs damage the frontal cortices, particularly the prefrontal areas involved in both emotional and cognitive functions, with a consequence of decoding emotion deficits for people with substance abuse. The present study aims to explore the cognitive impairments in drug abusers through facial, body and disgust emotion recognition, expanding the investigation of emotions, processing, measuring accuracy and response velocity. Method: We enrolled 13 addicted to cocaine and 12 alcohol patients attending treatment services in Italy, comparing them with 33 matched controls. Facial emotion and body posture recognition tasks, a disgust rating task, and
\end{abstract}


Decoding emotion in drug-abusers

the Barrat Impulsivity Scale were included in the experimental assessment. Results: We found that emotional processes are differently influenced by cocaine and alcohol, suggesting that these substances impact diverse cerebral systems. Conclusion: The contribution made by the duration of consumption on emotional processing seems far less important than for cognitive processes. Drug abusers seem to be slower on elaboration of emotions and, in particular, of disgust emotion. Considering that the participants were not impaired in cognition, our data support the hypothesis that emotional impairments emerge independently from damage to cognitive functions.

Keywords: emotional processing, disgust, cocaine dependence, alcohol dependence, face, body

\section{Introduction}

Drug users affect several neural systems at the subcortical and cortical levels, causing cognitive and emotional impairments (Fernández-Serrano et al., 2010; Berlingeri et al., 2017; Guirado et al., 2020;). Exposure and drug dependence, comprising recreational use only, impair different regions of the prefrontal cortex (Goldstein \& Volkow, 2002). Although there are differences in the induced impairments depending on the diverse drug dependence, there are also relevant commonalities. Excitant drugs such as amphetamine and cocaine and cocaine users, for example, show altered functioning of the prefrontal cortex (PFC) of users (Ernst et al., 2000; Huang et al., 2020; Volkow et al., 1993) as well as in alcohol users, particularly relating the medial prefrontal cortex (Klenowski, 2018). Even recreational use of cannabis and psychostimulants has been associated with mild executive deficits (Price et al., 2015; Leland \& Paulus, 2005; Bechara, 2001; Hall \& Solowij, 1998). Therefore, the PFC cerebral area is crucial in self-monitoring (Bonfiglio et al., 2019; Mazzoleni et al., 2019) and selfcontrol (Bonfiglio et al., 2020; Bonfiglio et al., 2021); the more exposure there is, the greater 
Decoding emotion in drug-abusers

the level of dependence (Bellingeri et al., 2017; Volkow et al., 2007). Furthermore, prefrontal cortex dysfunction, known to be primarily involved in decision-making processes, prevents good compliance with any treatment (Bernardin et al., 2014; Penberthy et al., 2010).

There are several studies on the cognitive disorders caused by drug abuse and the emotional decoding of drug abusers' competence.

Emotion recognition from faces has been extensively investigated in individuals with alcohol use disorder. Most studies identified impairments in the decoding of emotions from faces (Erol et al., 2017; D'Hondt et al., 2015; Quaglino et al., 2015; Valmas et al., 2014; Kornreich et al., 2013, 2002, 2001; Maurage et al., 2008; Foisy et al., 2007, 2005; Townshend and Duka, 2003; Philippot et al., 1999). However, some studies could not identify impairment in facial emotion recognition in alcohol users' patients (Kornreich et al., 2016; Sprah and Novak, 2008; Uekermann et al., 2005; Oscar-Berman et al., 1990; Cermak et al., 1989).

Many other studies with cocaine users have also revealed impairment in their ability to identify basic facial affect expressions (Hulka et al., 2013; Verdejo-Garcia et al., 2017, 2010; Romero-Ayuso et al., 2016; Woicik et al., 2009). However, a few studies have found specific alterations in fear and anger processing from faces in cocaine users (Ersche et al., 2015; Morgan and Marshall, 2013; Kemmis et al., 2007). Moreover, in polysubstance users, recognition of these emotions to last emotions was negatively correlated with cocaine use intensity (Fernandez-Serrano et al., 2010), while another study did not show an effect when assessed with complex stimuli (Kroll et al., 2018).

The emotional recognition problem is a crucial issue, as abusers frequently manifest problems in social interaction (Homer et al., 2008; Reay et al., 2006). Furthermore, the success of psychotherapy and psychosocial treatments such as residential treatments to induce the maintenance of drug withdrawal mainly relies on the therapeutic alliance, which is a key aspect of emotional processes (Digle et al., 2018; Fernández-Serrano et al., 2010). In real life, 
Decoding emotion in drug-abusers

people detect relevant social signs by decoding not only facial expressions but also emotional body postures (Adolphs, 2002; De Gelder \& Van den Stock, 2006).

Escalation and maintenance of drug dependence are associated with dysregulation of the anatomical structures that are also involved in the emotional circuit (Verdejo-García \& Bechara, 2010), such as the ventromedial prefrontal cortex, insula, and anterior cingulate cortex, anatomical areas associated with awareness of body emotional language (De Gelder et al., 2006).

There is evidence that dependence on alcohol causes not only an overestimation of the intensity of the emotional facial expressions of happiness, anger, and disgust (Foisy et al., 2007; Townshend \& Duka, 2003) associated with a poorer recognition of sadness (Frigerio et al., 2002) but also difficulties in discriminating anger and disgust (Townshend \& Duka, 2003; Kornreich et al., 2003; Martin et al., 2006). Selective alterations in fear recognition have been shown in cocaine and polysubstance psychostimulant abusers (Fernández-Serrano et al., 2010; Kemmis et al., 2007).

At the ontogenetic level, disgust is considered the refusal, or defense, from potentially harmful food products or contaminants for the individual (core disgust) (Rozin et al., 2009). However, with the evolution of society, four additional domains have been identified: poor hygiene, inappropriate sexual acts, death, and violation of the ideal body or external form, which in turn are linked to the broader domain of moral disgust (Rozin et al., 2009).

Contamination and moral disgust are both relevant elements in substance dependence, considering the modalities to assume different drugs and the recurrent violation of the body, such as drug injection. Identifying selective impairments of emotional decoding may contribute to a better focus on different forms of treatment.

In this study, we aimed to investigate the emotional decoding of abusers of alcohol and cocaine, including body posture recognition and the processing of disgust, and to explore the 
Decoding emotion in drug-abusers

ability to express these emotions (Sedda et al., 2017) by measuring both accuracy and velocity in terms of reaction times. Furthermore, we will investigate the cognitive competencies typically associated with the PFC. We believe that our study will provide preliminary data concerning (i) the impact of cocaine and alcohol on emotional processing, (ii) the influence of the duration of consumption of both substances on emotional processing, and finally (iii) the putative influence of cognitive dysfunction related to the prefrontal cortex on emotional competencies.

\section{Methods}

\subsection{Participants}

We enrolled 25 individuals diagnosed with substance dependence (see Table 1 for demographic and clinical features) attending Italy's government specialist addiction treatment service. Thirteen participants were primarily addicted to cocaine and 12 to alcohol. All were right-handed, and none showed pathological gambling. Only four individuals were under methadone treatment at the time of the experiment. Inclusion criteria to participate in the study were i) diagnosis of substance dependence according to the DMS-IV TR criteria, ii) absence of brain damage due to other diseases (i.e., traumatic brain injury), iii) absence of sensory or neurological disorders (i.e., blindness, dementia) and iv) abstinence from the substance in taking at least 55 days before the experiment.

Thirty-three participants were recruited as a control group at the University of Pavia (see Table 1 for demographic features). Inclusion criteria for these subjects were i) absence of substance abuse/dependence (with the exclusion of drinks, if moderate drinking - on average less than ten drinks per week), ii) absence of brain damage due to other diseases (i.e., traumatic brain injury), iii) absence of sensory or neurological disorders (i.e., blindness, 
Decoding emotion in drug-abusers

dementia), iv) absence of psychiatric or affective disturbances diagnosed by a specialist and v) absence of drug treatment.

[Insert here Table 1]

\subsection{Materials}

\section{Facial Emotion Recognition (FER)}

The FER is composed of male and female faces taken from the Ekman and Friesen series (Ekman \& Friesen, 1976), expressing one of the following emotions at full intensity: fear, sadness, happiness, and anger. Surprise was not included in the set, as previous studies reported that even healthy individuals frequently mistake this emotion for fear (Rapcsak et al., 2000). Furthermore, disgust has been excluded from obtaining a completely comparable set to the one adopted for postures (see BEAST description below). The task includes 12 displays for each emotion, portrayed by four individuals, leading to 48 trials. Stimuli were presented centrally, interspersed with a fixation cross between trials (1000 ms), and remained on the screen until the participant's response. Five labels (corresponding to the four emotions presented on the test and to an "I do not know" option) were shown below the screen and attached to the computer keyboard. Participants had to press the label corresponding to the emotion of the target image with their dominant hand. They had to answer as quickly and accurately as possible, but there was no time limit to complete a trial. The order of images was randomized across participants and within the same subject. We did not provide any feedback on performance accuracy during the experiment. Subjects were instructed to use the "I do not know answer" fewer times as possible.

\section{Body Emotion Recognition (BEAST)}

Stimuli consisted of male and female whole bodies expressing one of the following emotions: fear, sadness, disgust, happiness, and anger. Images were taken from the Bodily 
Decoding emotion in drug-abusers

Expressive Action Stimulus Test - BEAST (De Gelder \& Van den Stock; 2011). This task includes four displays for each emotion, displayed by four individuals, leading to 48 trials. Stimuli were presented, and responses were recorded with the same procedure as for the FER task.

\section{Disgust Rating Task (DRT)}

This task is composed of pictures depicting fear, sadness, happiness, and anger as controls and images displaying disgusting scenes or items (Sedda et al., 2017; Bottini et al., 2014). Pictures are taken from the International Affective Pictures System (IAPS; Lang et al., 2008) and the internet. For disgust, we presented 24 images: 4 images related to food, four related to body products, two related to animals, two related to contamination, four related to death, four pictures related to envelope violations, and four images related to hygiene. Twelve control images are also shown, with four images for each emotional category. Participants were presented with 36 real-life pictures and asked to rate the intensity of the picture. Ratings can range from 1 (not at all disgusting) to 7 (completely disgusting). Participants are asked to press one of the seven possible buttons on the keyboard using the dominant hand as rapidly as possible for each image. Stimuli are presented centrally until the subject's response, interspersed with a fixation cross $(1000 \mathrm{~ms})$.

\section{Barratt Impulsiveness Scale (BIS)}

This self-report scale (Fossati et al., 2001) is used to measure impulsiveness. It comprises 30 items that yield six first-order factors related to the construct measured (attention, motor, self-control, cognitive complexity, perseverance, and cognitive instability impulsiveness) and three second-order factors (attentional, motor, and nonplanning impulsiveness). The answers are given on a 4-point Likert scale. We adapted the scale for computer administration. Items were shown on the computer screen with no randomization to compare to the original version. Subjects were provided with different choices on the 
Decoding emotion in drug-abusers

computer keyboard and selected the most appropriate value among 1, 2, 3, 4, keys

corresponding to the original choices of 1: Never/Rarely; 2: Sometimes; 3: Often and 4:

Almost always/Always.

Brief Intelligence Test (TIB)

The TIB (Sartori et al., 1997) is the Italian equivalent of the "National Adult Reading Test” (Nelson, 1982) and assesses premorbid intelligent quotient (premorbid IQ). It consists of 54 words, 34 of which have an irregular pronunciation, while the others are control words with a high frequency of use. This instrument has also been adapted for a computer presentation. The participant's task is to read the word while the experimenter records the answer by pressing 1-2-3, according to whether the participant committed an error. Errors of pronunciation or accent are coded with 1, errors of both pronunciation and accent are coded with two, and no errors are coded as 3 . The total number of errors for the irregular words gives the final score. Regression equations are used to estimate premorbid IQ, taking into account the participant's score, gender, education, and age (Sartori et al., 1997).

\section{Raven Advanced Progressive Matrices (RAPM)}

The RAPM (Basso et al., 1987) is used to measure nonverbal intelligence and reasoning abilities. It consists of 48 stimuli structured as multiple-choice questions. Items are presented in black ink on a white background and become increasingly difficult as progress is made through each set. For each test item, the subject is asked to identify the missing element that completes a pattern. Twelve items compose the training set, while 36 effective test items are used. Being adapted for a computer presentation, this task requires participants to choose among eight alternative answers, each corresponding to a number selected on the computer keyboard.

\subsection{Procedure}


Decoding emotion in drug-abusers

Each group was administered the whole battery. The experiment was conducted in a quiet room, with the computer (screen size 16") positioned on a desk approximately $50 \mathrm{~cm}$ from the participant's eyes. Tasks were administered through dedicated software (OpensesameC - Mathôt et al., 2012), which allows the collection of reaction time (RT) and accuracy. Participants were required to use their dominant hand to answer by pressing the appropriate key on the computer keyboard. The six tasks were presented in random order. In all tasks, participants were instructed to respond as quickly and as accurately as possible. Only accuracy is recorded in the TIB and in the RAPM, while RT is also collected for the other tests.

\subsection{Data Analyses}

Data were analysed through Statistical Package for Social Sciences (SPSS) version 20.0 for MAC (IBMC). Demographic variables were compared using independent samples $t$ tests when continuous and the Mann-Whitney U test when nominal or categorical.

Data from the DRT, BIS, TIB, and RAPM were analysed using one-way ANOVA procedures. Data from both the FER and the BEAST tasks were analysed through a mixed ANOVA with Group (Cocaine dependence, Alcohol dependence, Controls) as the between and Emotion (Anger, Fear, Sadness, and Happiness) and Task (FER versus BEAST) as within-subjects factors. This procedure was applied to accuracy (percentage of correct answers), RT (average reaction time for correct responses only), and IES (inverse efficiency score).

Post hoc comparisons were carried out using Bonferroni corrected multiple comparisons. Alpha level was set at .05. Effect sizes of significant effects are presented as partial eta squared $\left(\eta^{2}\right)$ values. 
Decoding emotion in drug-abusers

\section{Results}

\section{Demographic Variables}

This preliminary analysis confirmed no significant differences between controls and dependent individuals with respect to age and education ( $p=.23$ for age; $p=.993$ for gender; $\mathrm{p}=.686$ for education).

\section{RAPM and TIB Results}

One-way ANOVA showed a significant cognitive level difference between groups considering the RAPM scores $\left(F_{(2,55)}=5.35, p=.008 ; \eta^{2}=.16\right)$. Post hoc Bonferroni corrected estimated marginal means comparisons revealed a difference between the control group and individuals with alcohol dependence, with lower scores for this latter group (mean difference $=-10,52 ; p=.006)$. There were no significant differences between controls and dependent individuals with respect to $\operatorname{TIB}\left(\mathrm{F}_{(2,55)}=1.56, \mathrm{p}=.218 ; \eta_{\mathrm{p}}^{2}=.05\right)$.

\section{FER and BEAST Results}

For accuracy, we did not find any significant main effect of Group $\left(\mathrm{F}_{(2,50)}=.417, \mathrm{p}=\right.$ $\left..662 ; \eta_{\mathrm{p}}^{2}=.01\right)$, two-way interaction between Group and Emotion $(\mathrm{F}(6,150)=.37, \mathrm{p}=.008$; $\left.\eta_{p}^{2}=.01\right)$ or between Group and Task $\left(F_{(2,150)}=.37, p=.688 ; \eta_{p}^{2}=.01\right)$, or any three-way interaction between Group, Emotion and Task $\left(\mathrm{F}_{(6,150)}=.40, \mathrm{p}=.878 ; \eta_{\mathrm{p}}^{2}=.01\right)$.

Concerning RT, we found a main effect of Group $\left(F_{(2,49)}=5.06, p=.010, \eta_{p}^{2}=.17\right)$. Post hoc comparisons showed that individuals with dependence on alcohol generally recognized emotions slower than controls (absolute mean difference $=637.28 ; \mathrm{p}=.046$ ) and compared to individuals with dependence to cocaine (absolute mean difference $=607.93 ; \mathrm{p}=$ .041) (Figure 1).

\section{[Insert here Figure 1]}

We also found a significant two-way interaction between emotion and task $\left(\mathrm{F}_{(3,147)}=\right.$ $\left.12.50, \mathrm{p}=.001, \eta_{\mathrm{p}}^{2}=.20\right)$. We did not find any significant two-way interaction between 
Decoding emotion in drug-abusers

emotion and group $\left(\mathrm{F}_{(6,147)}=1.13, \mathrm{p}=.345 ; \eta_{\mathrm{p}}^{2}=.04\right)$ or between task and group $\left(\mathrm{F}_{(2,49)}=\right.$ $\left.1.76, p=.182 ; \eta_{p}^{2}=.07\right)$. We found a three-way trend between emotion and task and group $\left(F_{(6,147)}=2.12, p=.054, \eta_{p}^{2}=.08\right)$.

As dependent subjects and controls had different RAPM scores, we reran this analysis, including RAPM as a covariate. This control did not change the results; the above results were all confirmed.

To further explore the above interaction, we performed separate ANOVAs for each emotion.

Considering anger alone, we found a significant main effect of Group $\left(\mathrm{F}_{(2,54)}=4.93, \mathrm{p}\right.$ $\left.=.011 ; \eta_{\mathrm{p}}^{2}=.15\right) ;$ post hoc Bonferroni corrected estimated marginal means comparisons revealed a difference between the control group and individuals with alcohol dependence, with higher RT for this latter group (mean difference=-979.66; $\mathrm{p}=.017$ ). We did not find any significant interaction between Task and Group $\left(F_{(2,54)}=1.38, p=.258 ; \eta_{p}^{2}=.05\right)$.

No significant main effect of Group arises for fear $\left(\mathrm{F}_{(2,54)}=2.11, \mathrm{p}=.131 ; \eta_{\mathrm{p}}^{2}=.07\right)$ and no interaction between Task and Group $\left(\mathrm{F}_{(2,54)}=.94, \mathrm{p}=.396 ; \eta^{2} \mathrm{p}=.03\right)$.

Happiness analyses did not reveal any significant main effect $\left(\mathrm{F}_{(2,52)}=2.78, \mathrm{p}=.071\right.$; $\left.\eta_{\mathrm{p}}^{2}=.09\right)$ or interaction between Task and Group $\left(\mathrm{F}_{(2,52)}=1.07, \mathrm{p}=.35 ; \eta_{\mathrm{p}}^{2}=.04\right)$.

Considering sadness, we found a significant main effect of Group $\left(\mathrm{F}_{(2,54)}=5.37, \mathrm{p}=\right.$ $\left..007 ; \eta^{2} \mathrm{p}=.16\right)$; post hoc Bonferroni corrected estimated marginal means comparisons revealed a difference between the control group and individuals with cocaine dependence, with higher RT for this latter group (mean difference=-818.20; $\mathrm{p}=.017$ ). No significant interaction between Task and Group was found $\left(\mathrm{F}_{(2,54)}=1.58, \mathrm{p}=.214 ; \eta_{\mathrm{p}}^{2}=.05\right)$.

\section{IES Analysis - Trade-off Between Velocity and Accuracy}

We found a main effect of Group concerning RTs, suggesting that individuals with dependence on alcohol and cocaine are slower in recognition of emotions expressed by the 
Decoding emotion in drug-abusers

face and the body than controls. However, as no main effect emerged for accuracy, these findings could only represent a trade-off between speed and accuracy. This effect could be plausible considering that no time limit has been assigned for these tasks. The inverse efficiency score (IES) (Bruyer \& Brysbaert, 2011) is a combined index accounting for speed and error rates. Thus, in the current study, such a conversion allows controlling the impact of accuracy on the speed of responses. This measure provides a more reliable and stable measure of emotional impairment when recognition is intact. The IES is calculated by dividing the RT value by the accuracy score.

When considering IES, the main effect of Group was significant $\left(\mathrm{F}_{(2,44)}=5.26, \mathrm{p}=\right.$ $\left..009, \eta_{\mathrm{p}}^{2}=.19\right)$, suggesting a trade-off between accuracy and RT. Post hoc comparisons showed that individuals with dependence on alcohol had higher IES scores than controls (absolute mean difference $=9.652 ; \mathrm{p}=.030)$ and individuals with dependence on cocaine $($ absolute mean difference $=8.130 ; \mathrm{p}=.04)($ Figure 2$)$.

\section{[Insert here Figure 2]}

We found no significant two-way interaction between emotion and group $(\mathrm{F}(3,132)=$ $\left.1.96, \mathrm{p}=.071, \eta_{\mathrm{p}}^{2}=.08\right)$ or between task and $\operatorname{group}\left(\mathrm{F}_{(2,44)}=.88, \mathrm{p}=.420 ; \eta_{\mathrm{p}}^{2}=.04\right)$ and no significant three-way interaction between emotion and task and group $\left(\mathrm{F}_{(6,132)}=1.85, \mathrm{p}=\right.$ $\left..094, \eta_{\mathrm{p}}^{2}=.08\right)$. These findings suggest that individuals with dependence are significantly slower in performing face and body posture recognition of emotions. They need much more time to reach the same accuracy as individuals without dependence. As subjects with dependence and controls had different RAPM scores, we reran this analysis, including RAPM as a covariate. This control did not change the results.

\section{DRT Results}

When taking into account RT, the analysis revealed a main effect of Group for food pictures $\left(\mathrm{F}_{(2,56)}=3.85 ; \mathrm{p}=.028 ; \eta_{\mathrm{p}}^{2}=.13\right)$. For the FER and BEAST tasks, post hoc 
Decoding emotion in drug-abusers

comparisons showed that individuals with dependence on alcohol were generally slower in recognition than controls (absolute mean difference $=1304.58 ; \mathrm{p}=.035$ ). No differences were found between groups in ratings of amputation images $\left(\mathrm{F}_{(2,57)}=.081 ; \mathrm{p}=.923 ; \eta_{\mathrm{p}}^{2}=.003\right)$, animal images $\left(\mathrm{F}_{(2,57)}=.95 ; \mathrm{p}=.392 ; \eta_{\mathrm{p}}^{2}=.03\right)$, product images $\left(\mathrm{F}_{(2,57)}=2.39 ; \mathrm{p}=.101 ; \eta^{2} \mathrm{p}\right.$ $=.080)$, contamination images $\left(\mathrm{F}_{(2,57)}=.58 ; \mathrm{p}=.944 ; \eta_{\mathrm{p}}^{2}=.080\right)$, death images $\left(\mathrm{F}_{(2,55)}=.88\right.$; $\left.\mathrm{p}=.421 ; \eta_{\mathrm{p}}^{2}=.03\right)$, hygiene-related images $\left(\mathrm{F}_{(2,57)}=.17 ; \mathrm{p}=.184 ; \eta_{\mathrm{p}}^{2}=.06\right)$ and control images $\left(\mathrm{F}_{(2,56)}=.69 ; \mathrm{p}=.501 ; \eta_{\mathrm{p}}^{2}=.02\right)$. Including the RAPM as a covariate did not change the results.

When taking into account rating, no differences were found between groups for amputation images $\left(\mathrm{F}_{(2,55)}=2.87 ; \mathrm{p}=.65 ; \eta_{\mathrm{p}}^{2}=.09\right)$, animal-related images $\left(\mathrm{F}_{(2,56)}=.52 ; \mathrm{p}=\right.$ $\left..597 ; \eta_{\mathrm{p}}^{2}=.02\right)$, body product images $\left(\mathrm{F}_{(2,57)}=2.2 ; \mathrm{p}=.119 ; \eta_{\mathrm{p}}^{2}=.075\right)$, contamination images $\left(\mathrm{F}_{(2,56)}=.09 ; \mathrm{p}=.613 ; \eta_{\mathrm{p}}^{2}=.004\right)$, death images $\left(\mathrm{F}_{(2,56)}=.49 ; \mathrm{p}=.613 ; \eta_{\mathrm{p}}^{2}=.02\right)$, hygiene-related images $\left(\mathrm{F}_{(2,56)}=1.27 ; \mathrm{p}=.287 ; \eta^{2} \mathrm{p}=.04\right)$ and control images $\left(\mathrm{F}_{(2,55)}=.3 .02\right.$; $\left.\mathrm{p}=.057 ; \eta_{\mathrm{p}}^{2}=.10\right)$

\section{BIS Results}

A trend between groups emerged from the one-way ANOVA comparison $\left(\mathrm{F}_{(3,43)}=\right.$ $\left.3.15, \mathrm{p}=.050 ; \eta_{\mathrm{p}}^{2}=.10\right)$, indicating slightly higher scores, hence greater impulsivity, in individuals with dependence on cocaine (absolute mean difference: $6.83 ; \mathrm{p}=.050$ ). No significant differences were found across the other groups.

\section{Clinical Data Analyses}

Taking into account the onset of drug dependence for the primary substance of dependence, the days of abstinence, and the type of secondary substance, we did not find any significant correlation with any of the measures we adopted to explore emotional processing (Spearman's or Pearson correlations, $\mathrm{p}>.05$ ). 
Decoding emotion in drug-abusers

\section{Discussion}

Individuals with dependence, regardless of the substance abused, show impairments of the prefrontal cortex (Koob \& Volkow, 2010; Goldstein \& Volkow, 2002). This cerebral structure is crucial in monitoring executive functions and emotional processes (Adolphs, 2002). Both of these components are relevant in complex behaviors such as decision making, which is central for compliance with treatments and the maintenance of drug withdrawal (Berlingeri et al., 2017; Bernardin et al., 2010). We speculate that emotional processing impairments that reduce the ability to decode social signs relevant for interaction and communication also negatively affect drug abuse treatment (Fernández-Serrano et al., 2010). Very little is known about emotional processing and dependence; in particular, the results on facial emotion recognition are mixed (Kornreich et al., 2003).

This study aimed to detail the emotional profile of individuals with dependence on psychostimulants or depressor drugs by expanding on recognition of body postures and disgust processing. We found that individuals with dependence on alcohol and cocaine can accurately recognize emotions from the face and the body, regardless of the emotional category. However, weighing accuracy and velocity rules out a trade-off that suggests that these individuals need significantly more time to reach the same accuracy as individuals without dependence. Similarly, individuals with alcohol dependence are generally slower than controls. There are already studies reporting that alcohol abusers need significantly more time than controls "to answer accurately to questions about the emotional decoding of the emotional facial expression task, regardless of the exposure time of the stimulus, and the type of answer expected" (Foisy et al., 2007, p. 39). Based on this observation, using time-limited tasks might also help appreciate significant differences in terms of accuracy. The results on alcohol abusers suggest that the entire emotional system has "slowed down" despite withdrawal from the abuse. 
Decoding emotion in drug-abusers

We did not find the same effect in cocaine abusers. Similarly, Woicik and colleagues (Woicik et al., 2009) found that cocaine abusers are not different from controls in facial emotion recognition tasks. Previous studies testing the accuracy on polyabusers showed that the quantity could explain the impairment of emotions in recognizing facial expressions in the use of substances throughout the entire lifespan (Fernández-Serrano et al., 2010).

We distinguished and compared participants based on their primary dependence and found that the secondary abused substance does not seem to influence emotional processing. However, our data show that cocaine abusers are slower in recognizing disgusting stimuli if they belong to the "food" category and show higher BIS scores than controls. What we have found is in agreement with the conclusions of a recent meta-analysis (Bora \& Zorlu, 2017); however, our results outline a more accurate profile for the different forms of disgust. These findings also agree with previous studies showing a significant impact of cocaine on emotional and inhibition processing (Fernández-Serrano et al., 2010). Prolonged cocaine use affects the striatum (Koob \& Volkow, 2010), connected through serial and parallel pathways to the basal ganglia and the prefrontal cortex (Pierce \& Vanderschuren, 2010). Both of these structures are involved in food processing. Interestingly, the anatomical structures of the reward system appear to be dysfunctional in both subjects with food intake dysregulation and cocaine abuse (Berridge et al., 2009; Stice et al., 2008).

\section{Conclusion}

Although preliminary, we believe that this study provides useful information for more focused clinical settings. We enrolled drug abusers with the primary and secondary substances of use, considering that these individuals are the most representative of this population. Investigating the basic emotional processes seems helpful to better understand more complex affective states such as depression, anxiety, and dysthymia, all clinical 
Decoding emotion in drug-abusers

conditions that relevantly prevent a good response to specific treatments to reduce relapse into abuse.

In conclusion, the impact of cocaine and alcohol on emotional processing is different, suggesting that their effects are related to the impairment of other neural systems. Finally, we also demonstrated that emotional decoding could be damaged independently of cognitive dysfunction considering that our sample did not show any significant cognitive disorder either before or after dependence.

\section{Limitations and future directions}

Despite the important strengths of the present study, future research should consider addressing some important limitations, such as the low number of subjects involved in the study and the nonbalanced frequency distribution of the participants in relation to their substance. These limits are, however, linked to the characteristics of the subjects who access addiction care services.

\section{Informed Consent}

All procedures followed were in accordance with the ethical standards of the responsible committee on human experimentation (institutional and national) and with the Helsinki Declaration of 1975, as revised in 2000. Informed consent was obtained from all patients for inclusion in the study.

\section{Declarations}

Informed consent was obtained from all individual participants included in the study.

\section{References}


Decoding emotion in drug-abusers

Adolphs, R., 2002. Neural systems for recognizing emotion. Current Opinion in Neurobiology, 12(2), 169-77

Basso, A., Capitani, E., Laiacona, M., 1987. Raven's colored progressive matrices: normative values on 305 adult normal controls. Functional Neurology, [Internet], 2(2), 189-194. Available from: http://europepmc.org/abstract/MED/3666548

Bechara, A., Dolan, S., Denburg, N., Hindes, A., Anderson, S. W., \& Nathan, P. E. (2001). Decision-making deficits, linked to a dysfunctional ventromedial prefrontal cortex, revealed in alcohol and stimulant abusers. Neuropsychologia, 39(4), 376-389.

Berlingeri, M., Losasso, D., Girolo, A., Cozzolino, E., Masullo, T., Scotto, M., Sberna, M., Bottini, G., Paulesu, E., 2017. Resting state brain connectivity patterns before eventual relapse into cocaine abuse, Behavioral Brain Research, 327(1), 121-132

Bernardin, F., Maheut-Bosser, A., Paille F., 2014. Cognitive impairments in alcohol-dependent subjects. Front Psychiatry, 5(JUL), 1-6.

Berridge, K.C., Robinson, T.E., Aldridge, W., 2009. Dissecting components of reward: "liking”, "wanting”, and learning. Current Opinion in Pharmacology, 9(1), 6573.

Bora, E., \& Zorlu, N. (2017). Social cognition in alcohol use disorder: a metaanalysis. Addiction, 112(1), 40-48.

Bonfiglio, N. S., Renati, R., Agus, M., \& Penna, M. P. (2019). Validation of a substance craving questionnaire (SCQ) in Italian population. Addictive Behaviors Reports, 9, 100172. https://doi.org/10.1016/j.abrep.2019.100172 
Decoding emotion in drug-abusers

Bonfiglio, N. S., Renati, R., Parodi, D., Pessa, E., Rollo, D., \& Penna, M. P. (2020). Use of training with BCI (Brain Computer Interface) in the management of impulsivity. 2020 IEEE International Symposium on Medical Measurements and Applications (MeMeA), 1-5. https://doi.org/10.1109/MeMeA49120.2020.9137202

Mazzoleni, M., Previdi, F., \& Bonfiglio, N. S. (2019). Classification algorithms analysis for brain-computer interface in drug craving therapy. Biomedical Signal Processing and Control, 52, 463-472. https://doi.org/10.1016/j.bspc.2017.01.011

Salvatore Bonfiglio, N., Renati, R., Di Lucia, K., Rollo, D., \& Pietronilla Penna, M. (2021). The use of cognitive training, combined with tDCS, for craving reduction and inhibitory control improvement in cocaine dependence: A case study. 2021 IEEE International Symposium on Medical Measurements and Applications (MeMeA), 1-6. https://doi.org/10.1109/MeMeA52024.2021.9478681

Bottini, G., Brugger, P., Sedda, A., 2014. Is the desire for amputation related to disturbed emotion processing? A multiple case study analysis in BIID. Neurocase [Internet]. 21(3), 1-9. Available from: http://www.tandfonline.com/loi/nncs20

Bruyer, R., Brysbaert, M., 2011. Combining speed and accuracy in cognitive psychology: Is the Inverse Efficiency Score (IES) a better dependent variable than the mean reaction time (RT) and the Percentage of Errors? Psychologica Belgica [Internet]. 51(1), 5-13. Available from:

http://www.academia.edu/download/31056976/Bruyer__Brysbaert_2011.pdf

Cermak, L. S., Verfaellie, M., Letourneau, L., Blackford, S., Weiss, S., \& Numan, B. (1989). Verbal and nonverbal right hemisphere processing by chronic alcoholics. Alcoholism: Clinical and Experimental Research, 13(5), 611-617. 
Decoding emotion in drug-abusers

D’Hondt, F., de Timary, P., Bruneau, Y., \& Maurage, P. (2015). Categorical perception of emotional facial expressions in alcohol-dependence. Drug and alcohol dependence, 156, 267-274.

De Gelder, B., 2006. Towards the neurobiology of emotional body language. Nature Reviews Neuroscience, 7(3), 242-9.

De Gelder, B., Van den Stock J., 2011. The bodily expressive action stimulus test (BEAST). Construction and validation of a stimulus basis for measuring perception of whole body expression of emotions. Frontiers in Psychology, 2(AUG), 1-6.

Dingle, G. A., Neves, D. D. C., Alhadad, S. S., \& Hides, L. (2018). Individual and interpersonal emotion regulation among adults with substance use disorders and matched controls. British Journal of Clinical Psychology, 57(2), 186-202.

Ekman, P., Friesen, W.V., 1976. Pictures of facial affect. Palo Alto, CA, Consulting Psychologist Press.

Ernst, T., Chang L., Leonido-Yee, M., Speck, O., 2000. Evidence for long-term neurotoxicity associated with methamphetamine abuse. Neurology, 28(54).

Erol, A., Akyalcin Kirdok, A., Zorlu, N., Polat, S., \& Mete, L. (2017). Empathy, and its relationship with cognitive and emotional functions in alcohol dependency. Nordic journal of psychiatry, 71(3), 205-209.

Ersche, K. D., Hagan, C. C., Smith, D. G., Jones, P. S., Calder, A. J., \& Williams, G. B. (2015). In the face of threat: neural and endocrine correlates of impaired facial emotion recognition in cocaine dependence. Translational psychiatry, 5(5), e570-e570. 
Decoding emotion in drug-abusers

Fernández-Serrano, M. J., Pérez-García, M., Perales, J. C., \& Verdejo-García, A. (2010). Prevalence of executive dysfunction in cocaine, heroin and alcohol users enrolled in therapeutic communities. European journal of pharmacology, 626(1), 104-112.

Fernández-Serrano, M.J., Lozano, Ó., Pérez-García, M., 2010. Verdejo-García, A. Impact of severity of drug use on discrete emotions recognition in polysubstance abusers. Drug Alcohol Dependence, Jun. 1, 109 (1-3), 57-64.

Fernández-Serrano, M.J., Pérez-García, M., Schmidt Río-Valle, J., Verdejo-García, A., 2010. Neuropsychological consequences of alcohol and drug abuse on different components of executive functions. Journal of Psychopharmacology 24(9), 1317-1332.

Foisy, M. L., Kornreich, C., Fobe, A., D'Hondt, L., Pelc, I., Hanak, C.... \& Philippot, P. (2007). Impaired emotional facial expression recognition in alcohol dependence: do these deficits persist with midterm abstinence?. Alcoholism: Clinical and Experimental Research, 31(3), 404-410.

Foisy, M. L., Philippot, P., Verbanck, P., Pelc, I., Van Der Straten, G., \& Kornreich, C. (2005). Emotional facial expression decoding impairment in persons dependent on multiple substances: impact of a history of alcohol dependence. Journal of studies on Alcohol, 66(5), 673-681.

Fossati, A., Di Ceglie, A., Acquarini, E., 2001. Psychometric properties of an Italian Version of the Barratt Impulsiveness Scale-11 (BIS-11) in nonclinical subjects. Journal of Clinical Psychology, 57(6), 815-28.

Frigerio, E., Burt, D.M., Montagne, B., Murray, L.K., Perrett, D.I., 2002. Facial affect perception in alcoholics. Psychiatry Research, 113(1-2), 161-71. 
Decoding emotion in drug-abusers

Goldstein, R.Z., Volkow, N.D., 2002. Drug addiction and its underlying neurobiological basis: Neuroimaging evidence for the involvement of the frontal cortex. American Journal of Psychiatry, 159(10), 1642-52.

Guirado, R., Perez-Rando, M., Ferragud, A., Gutierrez-Castellanos, N., Umemori, J., Carceller, H.... \& Castillo-Gómez, E. (2020). A critical period for prefrontal network configurations underlying psychiatric disorders and addiction. Frontiers in behavioral neuroscience, 14.

Hall, W., Solowij, N., 1998. Adverse effects of cannabis. Lancet, 352(9140), 16116.

Homer, B.D., Solomon, T.M., Moeller, R.W., Mascia, A., DeRaleau, L. Halkitis, P. N., 2008. Methamphetamine abuse and impairment of social functioning: a review of the underlying neurophysiological causes and behavioral implications. Psychological Bulletin, 134(2), 301-10

Huang, S., Dai, Y., Zhang, C., Yang, C., Huang, Q., Hao, W., \& Shen, H. (2020). Higher impulsivity and lower grey matter volume in the bilateral prefrontal cortex in longterm abstinent individuals with severe methamphetamine use disorder. Drug and alcohol dependence, 212, 108040.

Hulka, L. M., Preller, K. H., Vonmoos, M., Broicher, S. D., \& Quednow, B. B. (2013). Cocaine users manifest impaired prosodic and cross-modal emotion processing. Frontiers in Psychiatry, 4, 98.

Kemmis, L., Hall, J. K., Kingston, R., \& Morgan, M. J. (2007). Impaired fear recognition in regular recreational cocaine users. Psychopharmacology, 194(2), 151-159. 
Decoding emotion in drug-abusers

Kemmis, L., Hall, J.K., Kingston, R., Morgan, M.J., 2007. Impaired fear recognition in regular recreational cocaine users. Psychopharmacology (Berl), 194(2), 151-9.

Klenowski, P. M. (2018). Emerging role for the medial prefrontal cortex in alcoholseeking behaviors. Addictive behaviors, 77, 102-106.

Koob, G.F., Volkow, N.D., 2010. Neurocircuitry of addiction. Neuropsychopharmacology [Internet]. Nature Publishing Group, 35(1), 217-38. Available from: http://dx.doi.org/10.1038/npp.2009.110

Kornreich, C., Blairy, S., Philippot, P. I. E. R. R. E., Hess, U., Noël, X., Streel, E.... \& Verbanck, P. (2001). Deficits in recognition of emotional facial expression are still present in alcoholics after mid-to long-term abstinence. Journal of studies on alcohol, 62(4), 533-542.

Kornreich, C., Brevers, D., Canivet, D., Ermer, E., Naranjo, C., Constant, E.... \& Noël, X. (2013). Impaired processing of emotion in music, faces and voices supports a generalized emotional decoding deficit in alcoholism. Addiction, 108(1), 80-88.

Kornreich, C., Foisy, M.L., Philippot, P., Dan, B., Tecco, J., Noël, X. et al., 2003. Impaired emotional facial expression recognition in alcoholics, opiate-dependent subjects, methadone-maintained subjects and mixed alcohol-opiate antecedent subjects compared with normal controls. Psychiatry Research, 119(3), 251-60.

Kornreich, C., Petit, G., Rolin, H., Ermer, E., Campanella, S., Verbanck, P., \& Maurage, P. (2016). Decoding of nonverbal language in alcoholism: A perception or a labeling problem?. Psychology of Addictive Behaviors, 30(2), 175. 
Decoding emotion in drug-abusers

Kornreich, C., Philippot, P., Foisy, M. L., Blairy, S., Raynaud, E., Dan, B... \& Verbanck, P. (2002). Impaired emotional facial expression recognition is associated with interpersonal problems in alcoholism. Alcohol and alcoholism, 37(4), 394-400.

Kroll, S. L., Wunderli, M. D., Vonmoos, M., Hulka, L. M., Preller, K. H., Bosch, O. G... \& Quednow, B. B. (2018). Sociocognitive functioning in stimulant polysubstance users. Drug and alcohol dependence, 190, 94-103.

Lang, P. J., Bradley, M. M., Cuthbert, B.N., 2008. International affective picture system (IAPS): Affective ratings of pictures and instruction manual. Gainesville, FL, Technical Report A- 8.

Leland, D.S., Paulus, M.P., 2005. Increased risk-taking decision-making but not altered response to punishment in stimulant-using young adults. Drug and Alcohol Dependence, 78(1), 83-90.

Martin, L., Clair, J., Davis, P., O’Ryan, D., Hoshi, R., Curran, H.V., 2006. Enhanced recognition of facial expressions of disgust in opiate users receiving maintenance treatment. Addiction, 101(11), 1598-605

Mathôt, S., Schreij, D., Theeuwes, J., 2012. OpenSesame: An open-source, graphical experiment builder for the social sciences. Behavioral Research Methods, 44(2), 314-24.

Maurage, P., Campanella, S., Philippot, P., Martin, S., \& De Timary, P. (2008). Face processing in chronic alcoholism: a specific deficit for emotional features. Alcoholism: Clinical and Experimental Research, 32(4), 600-606. 
Decoding emotion in drug-abusers

Morgan, M. J., \& Marshall, J. P. (2013). Deficient fear recognition in regular cocaine users is not attributable to elevated impulsivity or conduct disorder prior to cocaine use. Journal of Psychopharmacology, 27(6), 526-532.

Nelson, H.E., 1982. The National Adult Reading Test (NART): Test Manual. (0-25). Windsor, UK, NFER Nelson.

Oscar-Berman, M., Hancock, M., Mildworf, B., Hutner, N., \& Weber, D. A. (1990). Emotional perception and memory in alcoholism and aging. Alcoholism: Clinical and Experimental Research, 14(3), 383-393.

Penberthy, J.K., Ait-Daoud, N., Vaughan, M., Fanning, T., 2010. Review of treatment for cocaine dependence. Current Drug Abuse Review, 3(1), 49-62.

Philippot, P., Kornreich, C., Blairy, S., Baert, I., Dulk, A. D., Bon, O. L.... \& Verbanck, P. (1999). Alcoholics' deficits in the decoding of emotional facial expression. Alcoholism: Clinical and Experimental Research, 23(6), 1031-1038.

Pierce, R.C., Vanderschuren, L.J.M.J., 2010. Kicking the habit: the neural basis of ingrained behaviors in cocaine addiction. Changes, 35(2).

Price, J. S., McQueeny, T., Shollenbarger, S., Browning, E. L., Wieser, J., \& Lisdahl, K. M. (2015). Effects of marijuana use on prefrontal and parietal volumes and cognition in emerging adults. Psychopharmacology, 232(16), 2939-2950.

Quaglino, V., De Wever, E., \& Maurage, P. (2015). Relations between cognitive abilities, drinking characteristics, and emotional recognition in alcohol dependence: A preliminary exploration. Alcoholism: clinical and experimental research, 39(10), 20322038. 
Decoding emotion in drug-abusers

Rapcsak, S.Z., Galper, S.R., Comer, J.F., Reminger, S.L., Nielsen, L., Kaszniak, A.W. et al., 2000. Fear recognition deficits after focal brain damage: a cautionary note. Neurology, 54(3), 575-81.

Reay, J.L., Hamilton, C., Kennedy, D.O., Scholey, A. B., 2006. MDMA polydrug users show process-specific central executive impairments coupled with impaired social and emotional judgment processes. Journal of Psychopharmacology, 20(3), 385-8.

Romero-Ayuso, D., Mayoral-Gontán, Y., \& Triviño-Juárez, J. M. (2016). Emotional intelligence and risk perception in abstinent cocaine-dependent individuals. Actas espanolas de psiquiatria, 44(2), 72-78.

Rozin, P., Haidt, J., Fincher, K., 2009. Psychology. From oral to moral. Science, 323 (5918), 1179-80

Sartori, G., Colombo, L., Vallar, G., Rusconi, M. L., Pinarello, A., 1997. T.I.B.: Test di Intelligenza Breve per la valutazione del quoziente intellettivo attuale e premorboso. La Professione di Psicologo 1II-XXIV (inserto).

Sedda, A., Petito, S., Guarino, M., Stracciari, A., 2017. Identification and intensity of disgust: Distinguishing visual, linguistic and facial expressions processing in Parkinson disease. Behavioural brain research, 330, 30-36.

Sedda, A., Rivolta, D., Scarpa, P., Burt, M., Frigerio, E., Zanardi, G. et al., 2013. Ambiguous emotion recognition in temporal lobe epilepsy: The role of expression intensity. Cogn Affect Behav Neurosci [Internet], 13(3), 452-63. Available from: http://www.ncbi.nlm.nih.gov/pubmed/23430725. 
Decoding emotion in drug-abusers

Sprah, L., \& Novak, T. (2008). Behavioural inhibition system (BIS) and behavioural activation system (BAS) as predictors of emotional and cognitive deficits observed in alcohol abstainers. Psychiatria Danubina, 20(2), 184-193.

Stice, E., Spoorm S., Bohon, C., 2008. Relation of Reward from Food Intake and Anticipated Food Intake to Obesity: A Functional Magnetic Resonance Imaging Study. Journal of abnormal psychology, 117(4), 924-35.

Townshend, J. M., \& Duka, T. (2003). Mixed emotions: alcoholics' impairments in the recognition of specific emotional facial expressions. Neuropsychologia, 41(7), 773782.

Townshend, J.M., Duka, T., 2003. Mixed emotions: Alcoholics' impairments in the recognition of specific emotional facial expressions. Neuropsychologia, 41(7), 773-82

Uekermann, J., Daum, I., Schlebusch, P., \& Trenckmann, U. (2005). Processing of affective stimuli in alcoholism. Cortex, 41(2), 189-194.

Valmas, M. M., Mosher Ruiz, S., Gansler, D. A., Sawyer, K. S., \& Oscar-Berman, M. (2014). Social cognition deficits and associations with drinking history in alcoholic men and women. Alcoholism: Clinical and Experimental Research, 38(12), 2998-3007.

Verdejo-García, A., Bechara, A. A., 2010. Somatic-marker theory of addiction. Clinical Psychology, 56(Suppl 1), 48-62.

Verdejo-Garcia, A., Clark, L., \& Dunn, B. D. (2012). The role of interoception in addiction: a critical review. Neuroscience \& Biobehavioral Reviews, 36(8), 1857-1869. 
Decoding emotion in drug-abusers

Verdejo-Garcia, A., Verdejo-Román, J., Albein-Urios, N., Martínez-González, J. M., \& Soriano-Mas, C. (2017). Brain substrates of social decision-making in dual diagnosis: Cocaine dependence and personality disorders. Addiction biology, 22(2), 457467.

Volkow, N. D., Fowler, J. S., 2000. Addiction, a disease of compulsion and drive: involvement of the orbitofrontal cortex. Cerebral cortex, 10(3), 318-325.

Volkow, N.D., Fowler, J.S., Wang, G.J., Hitzemann, R., Logan, J., Schlyer, D.J., Dewey, S.L. Wolf, A. P., 1993. Decreased dopamine D2 receptor availability is associated with reduced frontal metabolism in cocaine abusers. Synapse, 14(2).

Volkow, N.D., Fowler, J.S., Wang, G.J., Swanson, J.M., Telang, F., 2007. Dopamine in drug abuse and addiction: results of imaging studies and treatment implications. Archives of Neurology, 64(11), 1575-9.

Woicik, P. A., Moeller, S. J., Alia-Klein, N., Maloney, T., Lukasik, T. M., Yeliosof, O.... \& Goldstein, R. Z. (2009). The neuropsychology of cocaine addiction: recent cocaine use masks impairment. Neuropsychopharmacology, 34(5), 1112-1122.

Woicik, P. A., Moeller, S.J., and Goldstein, R.Z., 2009. The Neuropsychology of Cocaine Addiction: Recent Cocaine Use Masks Impairment. Neuropsychopharmacology: official publication of the American College of Neuropsychopharmacology. 34(5), 11121122. 